\title{
COVID-19 and cytokine storm syndrome: can what we know about interleukin-6 in ovarian cancer be applied?
}

\author{
Antonio Macciò ${ }^{1 *}$, Sara Oppi ${ }^{2}$ and Clelia Madeddu ${ }^{3}$
}

\begin{abstract}
Improving early diagnosis along with timely and effective treatment of COVID-19 are urgently needed. However, at present, the mechanisms underlying disease spread and development, defined prognosis, and immune status of patients with COVID-19 remain to be determined. Patients with severe disease state exhibit a hyperinflammatory response associated with cytokine storm syndrome, hypercoagulability, and depressed cell-mediated immunity. These clinical manifestations, sharing similar pathogenesis, have been well-studied in patients with advanced ovarian cancer. The present review suggests treatment approaches for COVID-19 based on strategies used against ovarian cancer, which shares similar immunopathology and associated coagulation disorders.

The chronicization of the hyperinflammatory cytokine storm in patients with severe COVID-19 highlights a defective resistance phase that leads to aspecific chronic inflammation, associated with oxidative stress, which impairs specific T-cell response, induces tissue and endothelial damage, and thrombosis associated with systemic effects that lead to severe multi-organ failure and death. These events are similar to those observed in advanced ovarian cancer which share similar pathogenesis mediated primarily by Interleukin-6, which is, as well demonstrated in ovarian cancer, the key cytokine driving the immunopathology, related systemic symptoms, and patient prognosis. Consistent with findings in other disease models with similar immunopathology, such as advanced ovarian cancer, treatment of severe COVID-19 infection should target inflammation, oxidative stress, coagulation disorders, and immunodepression to improve patient outcome. Correctly identifying disease stages, based on available laboratory data, and developing a specific protocol for each phase is essential for effective treatment.
\end{abstract}

Keywords: Ovarian cancer, COVID-19, Immunopathology, Resistance, Tolerance, Interleukin-6, Oxidative stress, Corticosteroids

\section{Introduction}

At the end of 2019, an outbreak of atypical pneumonia was reported in Wuhan, China. Severe acute respiratory syndrome coronavirus 2 (SARS-CoV-2) was identified as the pathogen underlying this novel disease, later referred to as Corona Virus Disease 2019 (COVID-19). Since its first reported case, the infection has spread to other

\footnotetext{
* Correspondence: antoniomaccio56@gmail.com

'Department of Gynecologic Oncology, Businco Hospital, "Azienda di Rilievo Nazionale ad Alta Specializzazione G. Brotzu", Via Jenner, 09100 Cagliari, Italy Full list of author information is available at the end of the article
}

regions in China and other countries, and, despite aggressive containment efforts, the number of affected individuals is rising worldwide [1]. Furthermore, the fatality rate is very high, dominated mostly by the elderly and patients with comorbidities [2-4]. Patients with COVID-19 primarily present with fever, myalgia or fatigue, and dry cough. However, they may also develop dyspnea and hypoxemia within 1 week of disease onset, which may rapidly progress into acute respiratory distress syndrome (ARDS) or organ failure $[4,5]$.

C C The Author(s). 2021 Open Access This article is licensed under a Creative Commons Attribution 4.0 International License, which permits use, sharing, adaptation, distribution and reproduction in any medium or format, as long as you give appropriate credit to the original author(s) and the source, provide a link to the Creative Commons licence, and indicate if changes were made. The images or other third party material in this article are included in the article's Creative Commons licence, unless indicated otherwise in a credit line to the material. If material is not included in the article's Creative Commons licence and your intended use is not permitted by statutory regulation or exceeds the permitted use, you will need to obtain permission directly from the copyright holder. To view a copy of this licence, visit http://creativecommons.org/licenses/by/4.0/ The Creative Commons Public Domain Dedication waiver (http://creativecommons.org/publicdomain/zero/1.0/) applies to the data made available in this article, unless otherwise stated in a credit line to the data. 
COVID-19 develops through several stages, from mild to critically severe, thereby justifying an individualized response for each patient [6]. During the early disease stages, symptoms of severe acute respiratory infection can occur, with some patients rapidly develop ARDS and other serious complications, ultimately causing multiple organ failure. Therefore, early diagnosis and timely treatment is essential to improve patient outcome. At present, the mechanisms underlying disease spread and development, appropriate methods to determine prognosis, and immune status of COVID-19 patients remain under investigation.

The manifestation of severe forms of COVID-19 in a proportion of patients, highlights the inability of the immune system to counteract the viral infection. These patients develop hyperinflammation characterized by high levels of pro-inflammatory cytokines, primarily Interleukin (IL)-6, and other acute- phase proteins, including Creactive protein (CRP), fibrinogen, and ferritin. They also exhibit lymphopenia, especially reduced $\mathrm{CD} 3+$ and CD4+ T- cell counts, and immunodepression, as well as high levels of D-dimer and fibrinogen degradation products [7-11]. Zhou et al. [9], was among the first to assessed temporal changes of laboratory circulating markers in hospitalized patients with COVID-19 from illness onset and demonstrated that patients who did not survive had significantly higher and progressively increasing levels of IL- 6 , serum ferritin, and D-dimer beginning on days 7 to 10 compared with those who survived. Patients who did not survive also had progressive neutrophilia with concomitant lymphocytopenia, in more severe cases. These parameters define the neutrophil/lymphocyte ratio (NLR), which provides a consolidated prognostic parameter for other diseases [12, 13], including ovarian cancer [14-17]. Noteworthy, during hospitalization evaluation, fibrinogen and antithrombin levels were significantly low in non-survivors [18]. High IL-6, CRP, ferritin, and D-dimer levels, as well as lymphopenia, are predictors of fatality $[7,9,11]$. Furthermore, advanced age ( $\geq 65$ years), high fever $\left(\geq 39^{\circ} \mathrm{C}\right)$, comorbidities (e.g., hypertension or diabetes), and elevated end organ-related indices (e.g., aspartate aminotransferase, urea, and lactate dehydrogenase levels) are also associated with higher risk of developing ARDS [7]. A comparison of these hematological parameters in the mild and severe infection groups showed significant differences primarily in IL-6 and CRP levels, as well as coagulation function-related indicators (fibrinogen, ddimer and time-to-thromboplastin) [7]. Specifically, IL-6 levels $\geq 24.3 \mathrm{pg} / \mathrm{mL}$ and D-dimer $>0.28 \mu \mathrm{g} / \mathrm{L}$ were closely correlated with the occurrence of severe COVID-19, and with their combined detection provided the highest specificity and sensitivity for early prediction of disease severity and death. Hence, IL- 6 has been defined as the emblematic cytokine for this severe infection [9]. Importantly, inflammatory indexes (CRP) and NLR have been shown to be reliable parameters for treatment monitoring $[19,20]$. A study on 61 consecutive patients with COVID-19 infection treated at Beijing Ditan Hospital from January 13 to 31, 2020, demonstrated that NLR was a meaningful parameter for prognosis as well as for risk stratification and management, with a NLR cut-off value of 3.13 providing high sensitivity and specificity for the prediction of disease severity [21]. Accordingly, the authors suggested that patients that are $>50$ years of age with an NLR $>3.13$ may require intensive care, whereas those with an NLR of $<3.13$ and age $<50$ years could isolate at home or be treated in a community hospital setting. These indications can alleviate the current pressure on global health community due to insufficient medical resources.

These observations indicate that COVID-19 patients with severe disease exhibit a hyperinflammatory response, primarily driven by IL-6, associated with cytokine storm syndrome, blood hypercoagulability, and depressed cell-mediated immunity [22, 23]. At this regard, in 1998 we had demonstrated that high levels of pro-inflammatory cytokines such as IL-6, tumor necrosis factor (TNF)- $\alpha$, IL-1, and CRP are correlated with impaired T-cell responses in women with advanced epithelial ovarian cancer [24]. We have also previously demonstrated that increased levels of macrophagederived pro-inflammatory cytokines, primarily IL-6, during evolution of ovarian cancer, are associated with the onset of systemic symptoms, including anemia, anorexia, and fatigue, as well as peripheral, cardiac, and respiratory muscle wasting [25-29]. In 2005, for the first time, we reported that, in a population of advanced ovarian cancer assessed at diagnosis prior to any antineoplastic treatment, the severity of cancer-related anemia was associated with a status of chronic inflammation characterized by high levels of IL-6, CRP, and fibrinogen [28]. Additionally, hemoglobin was significantly positively correlated with the nutritional status, defined by leptin values, and inversely correlated with high level of oxidative stress, characterized by elevated reactive oxygen species (ROS) and reduced antioxidant enzymes [28]. In a larger cohort of patients with advanced cancer at diagnosis before antineoplastic treatment, where patients with ovarian cancer showed the most severe anemia, low hemoglobin levels were associated with high hepcidin and ferritin levels, which were positively correlated with IL-6 [30]. Consistently, a recent meta-analysis of iron metabolism in anemia associated with COVID-19 showed that patients with severe disease had lower hemoglobin and higher ferritin, and the mean ferritin levels significantly differed between survivors and nonsurvivors [31]. 
Additionally, in a landmark study of paraneoplastic thrombocytosis in patients with epithelial ovarian cancer, Stone et al. [32] conducted parallel clinical and experimental analyses and found that advanced disease was associated with thrombocytosis, which was significantly correlated with the levels of IL-6 and thrombopoietin and associated with a significantly shorter progression-free and overall survival. Moreover, the authors also showed that both in ovarian cancer animal model and in patients with ovarian cancer, blocking IL-6 production with small interfering RNA or siltuximab, an anti-IL-6 antibody, respectively, normalized platelet counts. Since then, a paracrine circuit involving IL-6, which increases the levels of fibrinogen and thromboplastin thereby causing thrombocytosis, has been found to be associated with increased thrombotic risk in patients with ovarian cancer and other neoplasms. Notably, among the different tumors, ovarian cancer has the highest incidence of tumor-associated thrombocytosis and the strongest experimental and clinical evidence on the role of inflammation (particularly IL-6) in the development of this paraneoplastic condition [33-35].

The above observations illustrate how COVID-19 follows the paradigm of chronic inflammation development attributed to the failure of the resistance phase, consequent to the inability of the adaptive immune system to eliminate the pathogen, together with simultaneous activation of deleterious compensatory mechanisms, similar to those of the tolerance phase [36]. Thus, our knowledge of these processes could help to develop a more effective rationale treatment strategy for COVID-19, rather than an empirical approach. Indeed, the initial phase of the COVID-19 cluster cases was not well understood, which could have caused errors in patients' evaluation and treatment, particularly those with severe infection. Thus, the present review further expands this field by suggesting a rational treatment approaches based on evidence from studies on other diseases with similar immunopathology, such as advanced ovarian cancer. Similarly, in a recent mini-review, Turnquist et al. [37], used lung cancer to illustrate the similarities between the cytokine storm of COVID 19 and that observed in cancer. However, the available data and the long-lasting research on similar immunopathology is even more evident in ovarian cancer.

\section{The phases of avoidance, resistance and tolerance during the COVID-19 infection}

Humans are readily infected by various viruses, however in most cases, resolve the infection with or without tissue damage. The host can protect itself from infectious disease using three distinct strategies: Avoidance, resistance, and tolerance [38]. Avoidance involves reducing the risk of exposure to infectious agents by avoiding contact with those possibly infected; this remains the most important preventive measure. Hence, public health measures to contain the virus by minimizing social contact have the essential role of avoiding widespread infection. Alternatively, resistance and tolerance rely on the host response, since they are a function of pathogen burden and immunogenicity, and on the ability of the immune system to mount an efficient response [39].

\section{Resistance phase}

Resistance reduces pathogen burden once the infection is established. During this phase, the immune system recognizes the antigenic diversity of the pathogen and, to the extent that the immune system is effective, eliminates it. In this stage, the activities of macrophages, dendritic cells, natural killer cells, $\mathrm{T}$ and $\mathrm{B}$ lymphocytes, and, in certain cases, neutrophils, are determinantal. These cells, in turn, release a range of molecules that can induce tissue damage and organ malfunction, including interferons (IFNs), cytokines, cationic proteins, lipid mediators, metalloproteinases, and ROS [40]. ROS accumulated in the mitochondria strongly contributes to tissue damage and endothelial dysfunction [41, 42], thereby activating the pathogenetic mechanisms of thrombosis. Indeed, alterations of the vascular endothelium results in altered generation of thrombin, both systemically and locally in the lungs of patients with severe pneumonia, resulting in the deposition of fibrin with subsequent tissue damage and coagulation pathology [43]. Importantly, adaptive immune effector cells can induce tissue damage. For instance, CD8+ T cells can directly destroy virus-infected cells, however, in some noncytopathic viral infections, such as those caused by HCV and HBV, the destruction of infected cells by CD8+ T effectors is also the primary cause of liver damage [44, 45]. Similarly, antibodies binding to the antigens presented on infected cell surface influence the activation of complement cascades which induce an inflammatory reaction, thereby contributing to tissue damage [40].

During COVID-19 infection, the primary site of injury is the lung [46]. Experimental analysis showed that SARS-CoV-2, the etiologic agent of COVID-19, uses angiotensin-converting enzyme 2 (ACE2), which is primarily expressed in a small subset of cells in the lung called type 2 alveolar cells, as a cell receptor to gain entry to the cell [47]. Additionally, it has been reported that SARS-CoV-2 directly infect alveolar macrophages; a key feature in SARS-CoV viruses-mediated pathogenesis [48]. Therefore, it is within the lungs that the hostpathogen clash occurs.

The initial phase of COVID-19 infection can be successfully controlled in most individuals. However, in some, it exhibits intrinsic properties making any attempt to control the virus result in tissue damage. The greatest 
tissue damage occurs in individuals with predisposing genetic, or acquired conditions, involving one or more components of the innate or adaptive defense system, or in older patients $[36,40]$.

Such tissue damage cause widespread necrosis, which induces an additional strong nonspecific inflammatory response, fundamentally driven by macrophages and their cytokines; hence, macrophages are the key cell type driving immunity during all phases of COVID-19 infection. Alveolar macrophages may be infected by the virus, which propagates inside the immune cells thereby escaping early induction of IFN response, which is involved in the initiation of the innate immune response. Meanwhile, infected macrophages show increased and dysregulated production of, among others, chemokines and pro-inflammatory cytokines, as well as procoagulant prothrombinase [49]. Moreover, alveolar macrophages activated by viral pathogen-associated molecular patterns and by cytokines/chemokines released by infected cells (including infected macrophages), represent the first line defense against viral infection at entry site and their behavior and polarization influence disease outcomes [50]. Macrophages during the early phases detect the infection and respond by inducing IFN release, which limits viral replication. Furthermore, through the release of IL1 , IL- 6 , and TNF- $\alpha$, macrophages modulate the activity of $\mathrm{CD}^{+} \mathrm{T}$ cells by inducing the production of IL-2; while also inducing the expression of the IL-2 receptor, particularly on cytotoxic $\mathrm{CD}^{+} \mathrm{T}$ cells [40]. However, prolonged and excessive production of pro-inflammatory cytokines and ROS by activated macrophages induce an inflammatory response that results in symptoms associated with sickness behavior [49] (Fig. 1). This is also observed in cancer [51]; in particular, in ovarian cancer, the study of tumor microenvironment in ascites offers the optimal condition to assess the relationship between the tumor and the immune system [52-54]. Indeed, the first study that demonstrated the peculiar metabolic changes of tumor microenvironment was carried out by Warburg in monocyte from peritoneal effusion induced by an abdominal implanted tumor (similarly to ovarian cancer) [55]. Hence, the role of tumor-associated macrophages with their metabolic changes (Warburg effect) and consequent polarization in promoting tumorassociated inflammation as well as tumor progression (invasiveness and metastatic potential) and immune response modulation have been extensively studied in ovarian cancer both in experimental models and ex vivo [51, 56-62]. In this context, we demonstrated, using the ascites of patients with advanced serous papillifery ovarian cancer, a prevalence of M1 cells and an association between M1 macrophage polarization and high levels of IL-6, hepcidin, and ROS production [63]. In the same study, we also demonstrated that IL-6 is key to M1 macrophage polarization, the synthesis of hepcidin and, consequently, the elevated circulating levels of ferritin, and that the anti-IL- 6 monoclonal antibody, tocilizumab, effectively inhibited M1 polarization, as well as hepcidin and IL-6 production [63]. We have identified, as a representative case among patients with COVID-19 admitted at the COVID hospital of Cagliari started from March 2020, a 61 years-old patient without comorbidities, affected by a worsening respiratory syndrome and pneumonia from COVID-19, and evaluated the phenotype of peripheral blood macrophages $[63,64]$. We found a prevalence of M1 polarized macrophage with a M1/M2 ratio of 3.1, which was parallel with our previous findings in advanced ovarian cancer patients [63, 64], associated with high circulating levels of CRP, IL-6, and ferritin, as well as lymphopenia. Similarly, in 2018, Thorsson, while determining the immune phenotype associated to several types of cancer, showed that ovarian cancer had the highest M1/M2 ratio, among other cancers, associated with a prevalence of CD8 + cells and cytokines made by activated Th1 and Th17 cells, including IL-6 [65].

The novel coronavirus encodes proteins that inhibit IFN signaling and contribute to evasion of the adaptive immune system, which is closely associated with disease severity [66]. In other SARS-COV infections, the virus can evade the IFN signaling both at the stage of IFN induction via ubiquitination and degradation of the RNA sensor adaptor molecules or via inhibiting IRF3 nuclear translocation, as well as at the stage of IFN secretion, by decreasing STAT1 phosphorylation [67-69]. Next, active replication of SARS-COV likely induces a delayed type I IFN response resulting in compromised early viral control and increased influx of pro-inflammatory macrophages $[66,70]$. At this point, all events associated with aspecific chronic inflammation become activated; therefore, the persistence of the virus and the activation of innate immunity result in excessive, prolonged nonspecific inflammation, which negatively impacts immunosurveillance [71]. These events are similar to those described ovarian cancer microenvironment and contribute to the well-known phenomena of immune editing and escape in cancer development [71, 72].

Hence, aspecific inflammation contributes to immunosuppression, thrombosis, and multi-organ failure, which, in turn, contribute to the development of severe COVID-19. Due to these events, the initial interaction between the pathogen and host transitions into a systemic disease characterized by specific symptoms with severe immunopathology [66]. Therefore, the immunopathology observed in the lungs of patients with COVID 19 is an unavoidable consequence associated with the immune defense. The degree of immunopathology is positively correlated with the magnitude and duration of the immune response; therefore, the optimal immune 


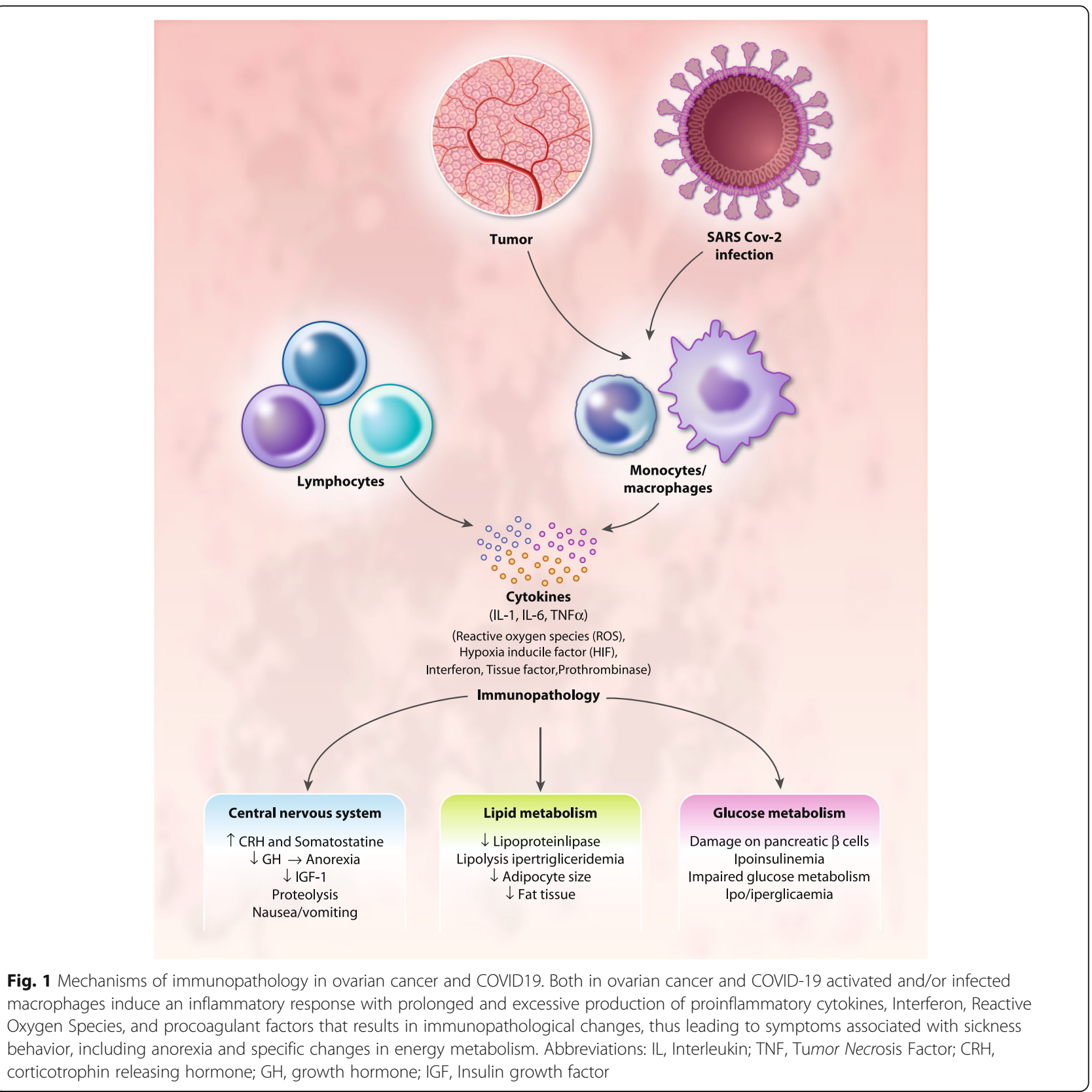

response can be defined as the balance between efficient clearance of the pathogen and an acceptable level of tissue damage [36].

\section{Tolerance phase}

The development of COVID-19, which overcomes the host defense mechanisms, results from ineffective immune resistance, which is followed by a chronic, aspecific inflammatory response exerted primarily by macrophages, that induces symptoms related to "sickness behavior" [36], including anorexia, fatigue, and anemia, which exemplifies the mechanism of tolerance. Tolerance is, therefore, a phase that occurs to limit the damage caused by chronic activation of the immune system following failed resistance [73].

Although the sickness behavior, typical of the tolerance phase, is assumed to be adaptive, it is not clear whether, or how, it benefits the infected host. For instance, anorexia and anemia may be attempts to preserve vital processes, however, they promote stress and damage in multiple tissues. Wang et al. has shown that anorexia is protective in bacterial sepsis while lethal in viral infections [74]. Although the resistance strategy is crucial for host protection, it has significant consequences. Indeed, the elimination of COVID-19 can be accompanied by excessive collateral tissue damage. 
Therefore, tolerance, the final defense strategy of the host, can result in further infection-induced damage [73]. These concepts are well known in advanced neoplastic disease, during which the transition from resistance to tolerance is responsible for anorexia/cachexia syndrome, which is the primary cause of death in several cancer patients; this syndrome has been the subject of our research for several years [29, 75-78]. The tolerance strategy may become activated when the inflammationdriven damage, caused by the immune system, equates that induced by the pathogen. Unlike resistance mechanisms, tolerance does not directly affect the pathogen burden, instead, it decreases host susceptibility to tissue damage or other fitness costs caused by the pathogen, or by the immune response $[36,73]$. Tolerance is also associated with damage-limiting events that do not happen in the most severe cases of COVID-19. During the infection, multiple physiological processes are significantly altered with often unknown rationale. Depending on the infection, these alterations can include profound changes in metabolism as well as in hepatic, renal, and cardiovascular functions. In principle, these responses can be either beneficial, induced as part of a general defense program, or, as in the case of COVID-19 infection, unintended, detrimental, and unavoidable consequences of infection.

\section{The role of necrosis in the evolution of COVID-19 infection}

During severe COVID-19 infection, tissue damage appears with widespread necrosis, which likely induces inflammatory signaling through the hypoxia-inducible factor (HIF)-1 pathway, thereby further activating macrophages and causing a switch in metabolic phenotype. Similarly, in cancer, HIF $1 \alpha$ coordinates the production of inflammatory mediators, including cytokines and chemokines, as well as the production of cyclooxygenase 2 and prostaglandins. These factors recruit and activate various leukocytes, most notably monocytes and macrophages, resulting in higher production of inflammatory mediators and thereby generating a cancer-related inflammatory microenvironment [51]. In ovarian cancer, which is one among the tumors with the strongest expression of HIF [79], hypoxic microenvironment is associated with a metabolic switch, of both cancer and immune cells, characterized by increased glycolytic activity, which influences tumor-associated macrophages (TAM) activation, polarization, and functions [80, 81]. Indeed, ovarian cancer ascites has a very hypoxic microenvironment where the role of HIF-induced release of pro-inflammatory and immunosuppressive factors and hypoxia-induced metabolic changes in modulating immune cells and impair T-cell functions can be clearly demonstrated [53].
Hence, understanding the specific functional activities of macrophages, which are key cell types in the evolution of COVID-19, is fundamental for identifying optimal therapeutic strategies. HIF-1 could serve as a critical transcriptional regulator of adaptive immunity and inflammation in COVID-19, and its signaling and the induction of aerobic glycolysis occur during the activation of certain immune cells, most notably M1 polarized macrophages. The HIF-1 pathway induces a metabolic switch in these cells, allowing them to appropriately respond to significant changes in energy requirements that occur upon activation, and to adapt to hypoxic conditions in inflamed and necrotic tissues. Necrotic foci, caused by of inflammation induced in the lung during the infection, generate difficult microenvironments for lymphocytes, in which they must adapt to hypoxia, acidosis, and redox stress to survive. During this phase of infection, the activation of the immune system requires specific modifications to the energy metabolism mechanisms used by cells, wherein the macrophagic cytokine IL-6 plays a key role. From a metabolic point of view, hypoxia and inflammation are inherently linked. For instance, decreasing oxygen levels induces metabolic changes to sustain ATP production; meanwhile quiescent immune cells, which are metabolically inert, require substantial metabolic reprogramming upon activation to provide sufficient ATP for effector functions. HIF-1 signaling drives such metabolic shift in the activated immune system, particularly in macrophages [82]. This metabolic shift induces macrophages polarization to M1 phenotype, which are the primary producers of IL-6 [83, 84]. Further, IL-6, through the signal transducer and activator of transcription 3 (STAT3) activation, contributes to metabolic reprogramming which induces aerobic glycolysis and downregulates mitochondrial oxidative phosphorylation by promoting pyruvate dehydrogenase kinase activity, thus shifting glucose metabolism toward the synthesis of lactate with increased levels of lactate dehydrogenase [85]. Notably, in ovarian cancer, in vitro studies have illustrated how IL-6 could induce, through STAT-3, the upregulation of HIF [86] as well as overexpression of hexokinase and associated glycolytic pathway [87].

In summary, macrophages are essential elements during the initial phase of the immune response, due to their antiviral properties, capacity to synthesize IFN, and interactions with, and recruitment of, helper and cytotoxic $\mathrm{T}$ lymphocytes. However, their persistent activation leads to the impairment of effective $\mathrm{T}$-cell responses by causing T-cell exhaustion, a condition where the lymphocytes, even when activated, are nonfunctional and subsequently undergo programmed cell death [71, 73], which may contribute to the observed lymphopenia in COVID-19. Recently, we have highlighted how blocking chronic inflammation, primarily driven by IL-6, may 
improve the efficacy of the currently available immunotherapy in cancer patients [71].

Recently, Wu et al. [7] showed that high IL-6 expression is one of the most important parameters indicative of severe COVID-19, which is associated with lymphopenia, a serious condition, and mortality. Similarly, we examined the effects of IL- 6 in patients with advanced cancer, particularly ovarian cancer, and found that its deleterious effects must be counteracted at all stages of metastatic neoplastic disease [25-28, 63].

Indeed, in ovarian cancer, the constitutive production of IL- 6 by cancer cells has been strongly demonstrated [88], as wells as IL-6 ability to promote tumor growth and progression through autocrine and paracrine actions $[89,90]$ and to cause specific immune and metabolic alteration that impact prognosis [91].

Also, in COVID-19, IL-6 is one of the key cytokines driving the immunopathology caused by the prolonged aspecific inflammation and correlated symptoms (Fig. 2).

\section{Interleukin- 6 actions and immunopathology}

IL-6, a $26-\mathrm{kDa}$ glycopeptide encoded by a gene on chromosome 7 , is produced by antigen-presenting cells such as dendritic cells, macrophages, and B cells. It is also produced by non-hematopoietic cells including keratinocytes, fibroblasts, epithelial cells, and neoplastic cells. IL-6 gene transcription is induced in normal tissues in response to stimuli including viral infection, bacterial endotoxin, lipopolysaccharide, as well as inflammatory cytokines and IFNs. IL- 6 binds ligandspecific $\alpha$-receptors (IL- 6 receptor- $\alpha$, also known as gp80) in either membrane-bound or soluble forms to activate signaling. This ligand receptor complex then binds universally expressed type I cytokine receptor IL-6 signal transducer/gp130 to activate three main pathways: STAT1/3, extracellular signal-regulated kinase and phosphatidylinositol-3-kinase (PI3K)/protein kinase B $(\mathrm{AKT}) /$ mammalian target of rapamycin (mTOR) pathways, of which, the Janus kinase (JAK)/STAT is the best characterized. Binding of gp130 activates associated JAKs, which then engage Src Homology 2 (SH2)-containing proteins, inclusive of STAT3. STAT3 phosphorylation leads to dimerization, nuclear translocation, DNA binding, and target gene regulation [26]. IL-6 is one of the major immunoregulatory cytokines present in the ovarian cancer microenvironment [92] while IL-6 antagonists may exert therapeutic effects against ovarian cancer [93].

IL-6 has pleiotropic actions that can affect virtually every organ. As widely demonstrated in ovarian cancer, IL-6 acts both locally, by conditioning the host immune response at the site of pathogen infection, and systemically, by altering energy metabolism, hematopoiesis, and nutritional status, as well as inducing severe endothelial damage, thereby negatively affecting patient prognosis $[25,26]$. Through its central role in the hypothalamicpituitary-adrenal axis, IL-6 contributes to sickness behavior response by causing mood disturbances and neurovegetative symptoms, including anorexia, fatigue, lethargy, malaise, difficulty concentrating, reduced activity, sleep impairment, and disinterest in activity [94]. In animal models of ovarian cancer, plasma and/or central nervous system (CNS) IL-6 was found to be associated with reduced locomotion and depression-like behaviors [95, 96]. Moreover, a significant association between plasma IL-6 and vegetative depression, disability, sleep disturbances, and fatigue has been demonstrated in patients with ovarian cancer at the time of surgery $[97,98]$. Consistently, Schrepf et al. [99] has demonstrated in patients with ovarian cancer that normalization of IL-6 levels following antineoplastic treatment was associated with declined self-reported fatigue, vegetative depression, and disability.

Neurological symptoms are also strongly associated with increased levels of ROS, which are associated with high IL-6 levels. The ROS inflammatory pathway may propagate within the brain and activate key molecular pathways involved in neurocognitive decline and neurological alterations [100, 101]. IL-6 also induces the transcription of several liver-specific genes in acute inflammatory states (Fig. 2), such as CRP and other acute-phase proteins such as Fibrinogen, in a dose- and time-dependent manner [102]. Using an in vitro model of ovarian cancer, it has been demonstrated that IL-6 produced by TAM attributes to the elevation of liverderived acute-phase proteins [103].

Acute-phase proteins, in turn, contribute to IL-6related pathogenesis, including immunodepression. Moreover, hepatic IL-6 induces the synthesis of hepcidin, ultimately causing functional iron deficiency, chronic inflammation-associated anemia [28], and thrombopoietin, which induces thrombocytosis [32], as specifically demonstrated in ovarian cancer [32, 33]. Notably, the increased levels of fibrinogen, high platelet count (thrombocytosis), and endothelial damage in patients with COVID-19 are possibly the primary factors responsible for pathogenesis of thrombosis and disseminated intravascular coagulation, of which the increased levels of D-dimer and reduced platelet count are the most evident indices [23]. Specifically, the development of disseminated intravascular coagulation is associated with progression of certain severe cases of COVID-19 from ARDS to death [7]. These factors explain the strong temporal correlations in severe COVID-19 patients observed between increases in the levels of IL-6, CRP, and Ddimer, and with lymphopenia and the development of progressive organ failure. 


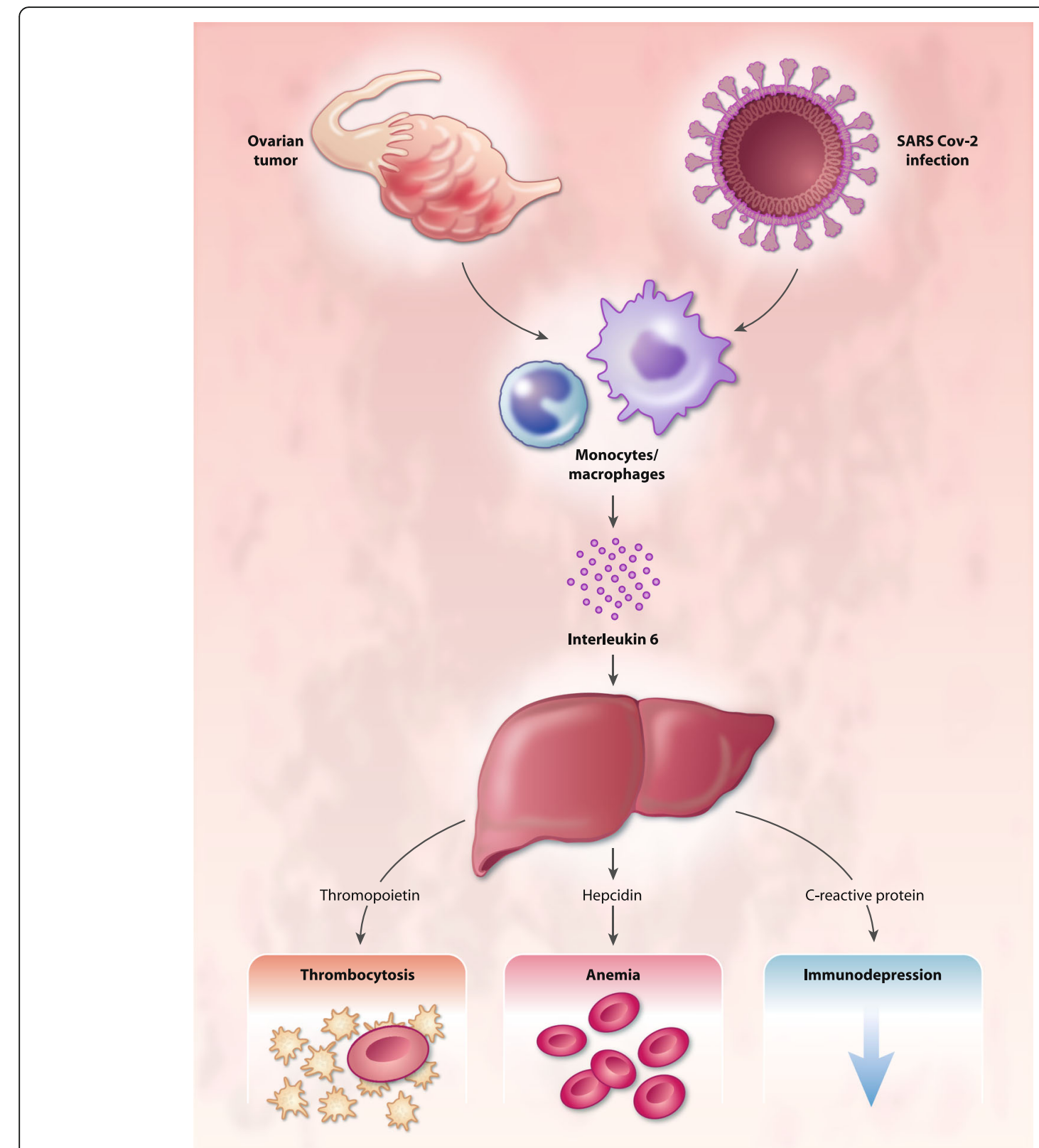

Fig. 2 Role of IL-6 in immunopathology associated to ovarian cancer and COVID-19. IL-6 is one of the key cytokines driving the immunopathology caused by prolonged aspecific inflammation. IL-6 induces the transcription of several liver-specific genes in acute inflammatory states, such as CRP, thrombopoietin, and hepcidin thus contributing to associated immunodepression, anemia and thrombocytosis (with related hypercoagulability)

IL-6 influences the effectiveness of the immune system in multiple ways. For instance, IL-6 can act as an activator, or an inhibitor, of T-cell responses, depending on the duration of its activity. Indeed, it initially participates in the activation of the immune response; however, its prolonged, chronic release ultimately contributes to immunosuppression. IL-6 can also suppress T-cell proliferation by inhibiting IL-2 synthesis, IL-2 receptor expression, and IL-2-dependent JAK/STAT signaling [26]. In fact, in patients with advanced ovarian cancer, we have demonstrated a correlation between high levels of IL-6 and the inability of lymphocytes to produce adequate level of IL-2 or express IL-2 receptor at physiological levels [24]. Noteworthy, a link between high levels of soluble IL2 receptor and lymphopenia of COVID-19 has been reported [104].

Moreover, high concentrations of IL- 6 may activate a STAT5-dependent negative feedback loop in $\mathrm{CD} 4^{+} \mathrm{T}$ cells, the primary producers of IL-2, thus altering the balance between STAT3-dependent $\mathrm{CD}^{+} \mathrm{T}$ cells, and 
STAT5-induced regulatory $\mathrm{T}$ cells [105]. Additionally, IL-6 may divert the immune system away from a Th1 response toward more immunosuppressive Th2 activity. Meanwhile, CRP, which is induced by IL-6, may interfere with the immunological mechanisms underlying the activity of IL-2 [106]. CRP is also involved in the binding of complement to cytotoxic $\mathrm{CD}^{+}$cells [107] and plays a key role in the inhibition of NK cell cytotoxicity [108]. Other negative effects exerted by IL- 6 on the immune system result from its regulation of cellular glucose uptake, glycolysis, and iron trafficking. IL-6 disrupts energy and iron metabolism, leading to T-cell exhaustion, characterized by a progressive loss of T-cell function [71]. IL-6 can also exert direct inhibitory effects on the PI3K/ Akt/ mTOR pathway, thereby inhibiting primary cellular energetic and anabolic processes [109]. Also, the systemic metabolic effects of IL-6 contribute to impaired T-cell energy pathways. Specifically, IL-6 signaling induces insulin resistance, alters protein, lipid, and fatty acid metabolism [85], and induces anemia [28] and anorexia [25], with consequent impairment of nutritional intake and utilization of energy substrates and microelements (e.g., glucose, iron, and zinc) that are fundamental for the activity of the main lymphocyte energy metabolic pathways (Fig. 3). To this regard, we had demonstrated in patients with advanced ovarian cancer a positive correlation between high IL-6 levels and impaired nutritional status, as evidenced by low levels of leptin [27]. Moreover, we have shown, in a large cohort of patients with advanced cancer evaluated at diagnosis before any antineoplastic treatment, where ovarian cancer patients showed the most severe anemia, that IL-6 correlated directly with the Glasgow Prognostic Score an inflammatory/ nutritional index defined by the CRP/albumin ratio [30]. Overall, IL-6 signaling can cause an energy deficiency condition that represses T-cell receptor (TCR)-related signaling, IFN production, cytotoxicity, and T-cell motility, with detrimental effects on the immune response [71]. Thus, inflammatory immune response can deplete $\mathrm{T}$ cells and affecting the outcomes of patient with COVID-19 leaving them prone to secondary infection [110].

Among the clinical phenomena associated with IL-6mediated immunopathology, muscle wasting, affecting respiratory muscles thereby contributing to respiratory dysfunctions, significantly impacts morbidity of patients with COVID19. IL-6 induces the loss of muscle mass [76]; for instance, IL-6 can exert systemic effects on energy metabolism, including the induction of peripheral muscle insulin resistance and the impairment of insulin signaling, which are associated with increased amino acid oxidation, negative energy balance, and muscle proteolysis (Fig. 3). Additionally, muscle loss is directly induced by IL-6-mediated activation of muscular STAT3/ NF-kB signaling and ubiquitin-proteasome system- mediated proteolysis in skeletal muscle. Muscle wasting caused by activation of the IL-6/STAT3 signaling cascade also involves the inhibition of the PI3K/Akt/mTOR pathway, which induces muscle protein synthesis (anabolism) [111]. To this regard, Pin et al. [112] showed that ovarian cancer can serve as an optimal preclinical model for studying the role of IL- 6 in inducing cancerassociated cachexia. The authors implanted ES-2 ovarian cancer cells intraperitoneally to simulate disseminated abdominal disease and malignant ascites formation and found severe weight loss with progressive muscle wasting via enhanced muscle protein catabolism associated with elevated tumor-derived IL-6 levels in plasma and ascites, elevated phospho-STAT3, reduced levels of phosphorylated AKT, and altered mitochondrial homeostasis and metabolism. Inhibition of the IL-6/STAT3 signaling restored muscle wasting [112]. The actions of IL- 6 on muscle wasting are dose- and time-dependent. Indeed, recent data showed that patients with COVID19 develop weight loss and cachexia that correlated with high levels of inflammatory parameters (CRP), impaired renal function status, and longer duration of COVID-19 disease [113]. Therefore, the prolonged exposure to high IL-6 in patients with severe COVID-19 may lead to serious muscle wasting, which significantly worsens lung functional capacity and, through the associated negative energy balance, contributes to organ failure, including respiratory failure, as similarly reported in other severe viral infectious diseases [114, 115].

\section{Role of oxidative stress in the evolution of COVID-19}

Chronic inflammation and macrophage activation induce oxidative stress. We have previously demonstrated that high levels of IL-6, CRP, and other pro-inflammatory cytokines in patients with advanced cancer was correlated with high levels of ROS and low levels of antioxidant enzymes $[27,116,117]$. Oxidative stress can negatively regulate immune response; high ROS levels induce specific alterations in TCR signaling proteins, including conformational changes in TCR $\zeta$ and LCK, thereby reducing their phosphorylation and signaling-induced calcium flux, with consequent suppression of antigen-mediated $\mathrm{T}$-cell responses [118]. In particular, ovarian cancer ascites exhibit high levels of ROS and it has been demonstrated that incubation with the cell-free ascites enhances the ROS level in $\mathrm{T}$ cells as well as in dendritic cells, with consequent impairment of the antigen-presenting capacity of DCs and inhibition of T-cell activation [119]. In vitro treatment with antioxidants, such as $\alpha$-lipoic acid and $\mathrm{N}$-acetyl cysteine, reversed the oxidoreductive state and restored the blastic response of lymphocytes isolated from patients with advanced-stage cancer $[120,121]$. These findings provided our group with the rationale for studies on the therapeutic effect of several antioxidants in patients with advanced 


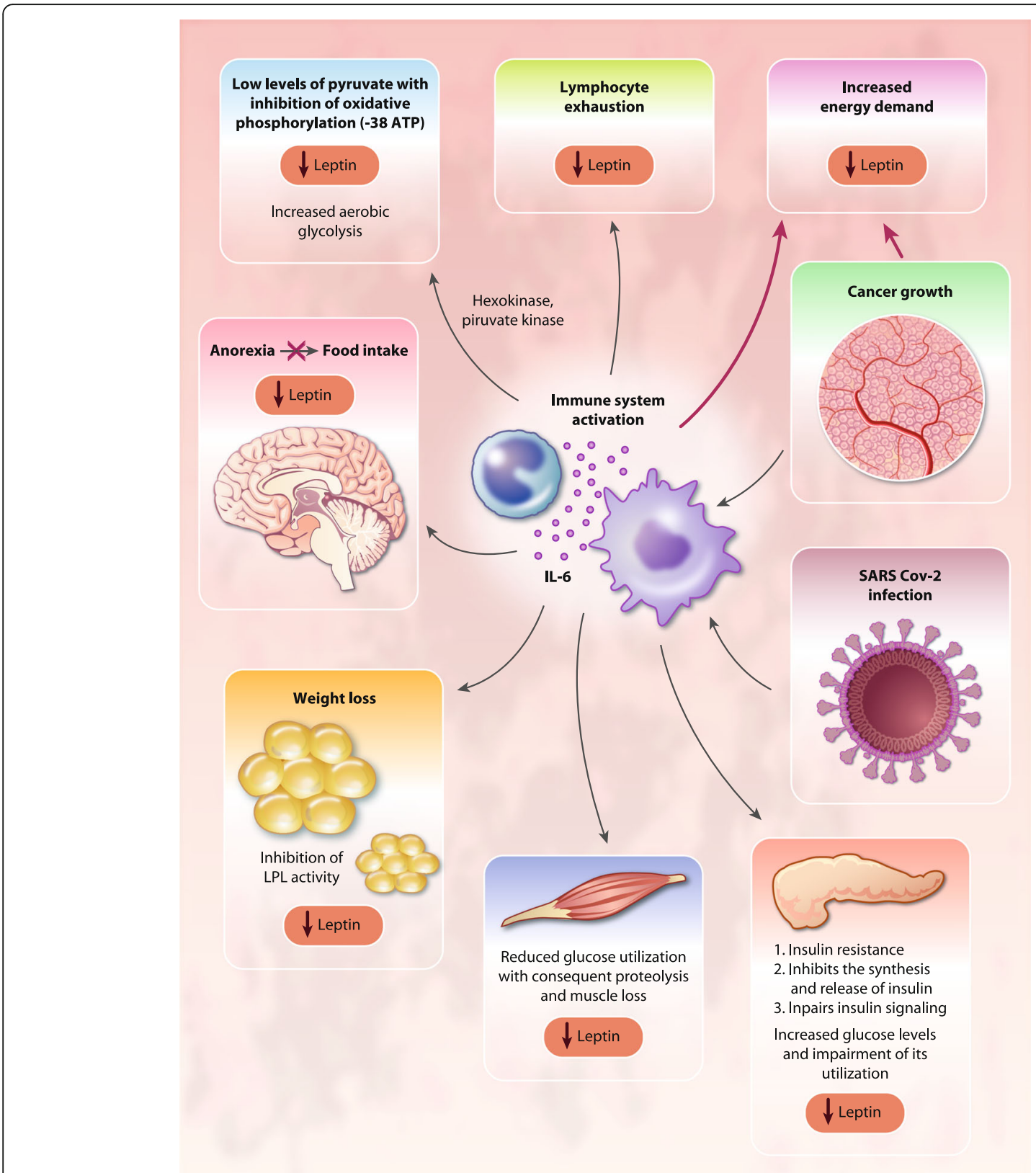

Fig. 3 Systemic effects of IL-6 in ovarian cancer and COVID-19. IL-6 exerts systemic effects on energy metabolism, including the induction of peripheral muscle insulin resistance and the impairment of insulin signaling, which are associated with increased amino acid oxidation, negative energy balance, and muscle proteolysis. Abbreviations: IL, Interleukin; LPL, lipoprotein-lipase

cancer [122-124], and particularly of a combined regimen targeting symptoms associated with inflammation and oxidative stress in patients with advanced ovarian cancer [29]. Of relevance, Wu et al. [7] has reported the treatment of patients with severe COVID-19 with antioxidants like glutathione and $\mathrm{N}$-acetyl cysteine. In this regard, we would like to mention our previous review on the role of carbocysteine, which focused primarily on the antiinflammatory properties of such an irreplaceable antioxidant agent [125].
Moreover, ROS overproduction is sensed by the nucleotide-binding domain, leucine-rich-containing family, pyrin domain-containing-3 (NLRP3) inflammasome, an intracellular multiprotein sensor of danger signals induced by pathogens or cellular stress, which, upon activation, serves as a platform for activation of the cysteine protease and Caspase-1, which subsequently induces the production of pro-inflammatory cytokines, including IL6. Further, ROS can directly oxidize thiol groups in the leucine-rich repeat domain of NLRP3 to activate the 
inflammasome pathway [126], which can further contribute to a prolonged, excessive inflammatory response in patients with COVID-19. This event may be common in elderly patients, the group with the highest COVID19-related mortality rate, due to a phenomenon referred to as inflammaging.

Inflammaging, the low-grade pro-inflammatory status associated with aging [127], could contribute to explain the more severe effects of COVID-19 in the elderly population. Some studies have suggested that, in healthy elderly individuals, the circulating levels of inflammatory cytokines are higher than in younger individuals, even in the absence of a comorbid disease $[128,129]$. The development of this chronic inflammatory status is attributed to activation of the inflammasome downstream of nuclear factor kappa-lightchain-enhancer of activated B cells (NF- $\mathrm{kB}$ ) signaling, which become stimulated by cellular stresses that occur during the aging process. Similarly, an increased activation of inflammasome and its contribution to chronic inflammation has been demonstrated in malignant ovarian cancer [130]. Aging is characterized by ROS-mediated mitochondrial damage, an increase in iron deposition, deregulation of $\mathrm{Ca}^{2+}$ and postabsorptive plasma cysteine homeostasis, as well as impaired autophagy and sirtuin activity secondary to aberrant insulin receptor signaling; events that are observed also in advanced ovarian cancer [131-133]. These altered pathways influence progressive increases in intracellular ROS level and oxidative stress [134]. Moreover, the aging process involves a progressive decline in cellular and organism-level function; in particular, defects in mitochondrial degradation further increases ROS production. Thus, oxidative stress in elderly patients stimulates the NF- $\mathrm{kB}$ signaling via multiple mechanisms, while enhancing inflammasome activation $[135,136]$.

The consequent ROS-induced inflammasome activation has been hypothesized to be associated with the chronic inflammation, endothelial damage and to thrombotic events in the elderly. In particular, in vivo and in vitro studies have indicated that aging is associated with an increase in the steady-state levels of IL- 6 mRNA resulting from enhanced binding of the redox-sensitive transcription factor NF-kB to the IL-6 promoter [137]. Consequently, older subjects present heightened basal levels of pro-inflammatory mediators, characterized primarily by mildly elevated levels of IL-6, which may contribute to their decreased pulmonary function and blunted immune responses to respiratory tract infections [138]. Thus, in the elderly, the inflammasome activation may further exacerbate the aspecific inflammatory response observed in COVID-19, making these patients more susceptible to the complications of this viral infection.

\section{COVID treatment strategy based on pathogenetic mechanisms}

The chronicization of the hyperinflammatory cytokine storm observed in patients with severe COVID-19 highlights a defective resistance phase that leads to aspecific chronic inflammation responsible for the impairment of an effective specific T-cell response and subsequent deterioration of patients' condition (tolerance phase), with systemic effects that can lead to severe multi-organ failure and death.

Thus, in the tolerance phase, targeting the symptoms consequent to chronic inflammation, such as thrombosis, anemia, anorexia, weight loss, muscle wasting is fundamental for an effective treatment strategy. Therefore, treatment with immunomodulatory and immunosuppressive drugs, such as glucocorticoids and low molecular weight heparin, to prevent or treat the associated thrombotic events, as well as administration of supportive drugs, such as antioxidants and lactoferrin, which help to restore the defective function of the adaptive specific immunity and modulate the altered iron metabolism, as observed in patients with advanced ovarian cancer [29, 139], may prove beneficial even in the absence of specific antiviral treatments. In a randomized clinical trial [140] we have demonstrated in patients with advanced cancer, primarily ovarian cancer, with chemotherapy-related anemia, that lactoferrin mobilized iron storage thereby reducing ferritin levels and increasing iron availability for erythropoiesis and heme proteins synthesis, such as myoglobin and cytochrome chain.

Indeed, corticosteroids significantly reduce mortality of critically ill COVID-19 patients [141]. In detail, the Randomized Evaluation of COVID-19 Therapy (RECOVERY) trial, a multicenter, randomized, open-label trial in hospitalized patients with COVID-19, showed that the mortality from COVID-19 was lower among patients who received dexamethasone than among those received standard care [142]. Also, a meta-analysis of seven randomized controlled trials including approximately 1700 patients with COVID-19 showed that systemic corticosteroids decrease 28-day mortality rate without safety concerns [143].

Furthermore, targeted drugs such anti-IL-6 monoclonal antibody (mAb), anti-IL-1 mAb, anti-TNF mAb, may counteract the cytokine storm syndrome. However, to date, results from the main randomized clinical trials on hospitalized patients with COVID-19 treated with the anti-IL-6 mAb, tocilizumab, remain controversial [144147]. Notably, the early use in severe patients has been reported to be associated with lower progression to mechanical ventilation and mortality [141, 142]. Further studies are ongoing [148]; while another anti-IL-6 mAb, siltuximab, is currently being tested in several ongoing randomized clinical trials [149]. 
Additionally, JAK inhibitors have been suggested as a promising potential agent against COVID-19 owing to their ability to inhibit both the JAK/STAT pathway, with its associated cytokine signaling, and AP2-associated protein kinase 1, which regulates SARS-CoV-2 endocytosis via the ACE receptor expressed on epithelial alveolar lung cells [22, 150].

Convalescent plasma is potentially effective against COVID-19, however, to date, only data from retrospective case series are available and adequately powered, randomized controlled trials remain warranted [151]. Similarly, anti-SARS-CoV-2 neutralizing mAbs (or mAb cocktails) are also under investigation in ongoing Phase 2 or Phase 3 clinical trials [152].

Undoubtedly, the gold standard is the prevention with vaccines and the use of antiviral therapy, particularly in the early stages of the disease (resistance phase); to this regard, several trials testing potential antiviral agents are underway [153]. Among them the most promising agent seems remdesivir; in a randomized clinical trial, compared with placebo, remdesivir shortened the time to recovery in adults hospitalized with COVID-19 and lowered respiratory tract infection [154]. Co-administration of antiviral agents with immunosuppressive/anti-inflammatory drugs, such as corticosteroids and JAK inhibitors are being evaluated [155].

As for SARS-CoV-2 vaccine, the preliminary results with RNA-based vaccines were positive. In particular, an ongoing multinational, placebo-controlled, observerblinded, pivotal efficacy trial, tested the efficacy and safety of the vaccine with BNT162b2, a lipid nanoparticle-formulated, nucleoside-modified RNA vaccine that encodes a prefusion stabilized, membrane-anchored SARS-CoV-2 full-length spike protein [156]. In the primary analysis, which included approximately 20,000 subjects for each arm, BNT162b2 was 95\% effective in preventing COVID19 (95\% credible interval, 90.3 to 97.6): Only eight cases were observed in the vaccine group as compared with the 162 in the placebo group. Among 10 cases of severe COVID-19 with onset after the first dose, nine occurred in placebo recipients and one in a BNT162b2 recipient. The safety profile of BNT162b2 was characterized by short-term, mild-to-moderate pain at the injection site, fatigue, and headache. The incidence of serious adverse events was low and similar both groups [156]. Another randomized, placebo-controlled study tested the mRNA1273 vaccine, with 30,000 adults receiving two $100 \mu \mathrm{g}$ doses 1 month apart. The interim data from the trial based on 95 cases estimated efficacy at $94.5 \%$; moreover, all severe cases as well as one COVID-19 related death occurred in the placebo group. At interim analysis, no serious adverse events occurred [157]. These results led to emergency authorization from the US Food and Drug Administration and conditional approval from the European Medicines Agency for these COVID-19 vaccines. More recently, the viral vector vaccine ChAdOx1 nCoV-19 showed an acceptable safety profile and has been found to be efficacious (an overall vaccine efficacy of 70.4\%) against symptomatic COVID-19 in an interim analysis of ongoing clinical trials including 11,683 participants [158].

Therefore, it is essential to define the clinical conditions of each patient with COVID-19 and identify the most appropriate treatment for each disease stage based on laboratory data essential to define the evolution of the infection $[7,9,22,23]$. In patients where the presence of few symptoms is prevalent (pauci-symptomatic subjects), the use of paracetamol, aspirin, and other cyclooxygenase-2 (COX2) inhibitors, appears to be more appropriate [159]. The role of aspirin is being investigated in patients with COVID-19 in RECOVERY trial [160]. Notably, in other SARS coronaviruses, COX-2 pathway could be directly activated by the virus, thus boosting prostaglandin production, and is involved in mediating viral RNA synthesis and replication as well as influencing antiviral lymphocyte response [161]. In patients with moderately symptomatic (mild severe) disease and altered inflammatory indices, the use of lowdose glucocorticoids and low molecular weight heparin at prophylactic dosage calculated based on body weight, rather than the standard dose of $4000 \mathrm{IU}$ often used in clinical practice, should be used. Meanwhile, in severe and terminal stages, the use of high dose glucocorticoids, low molecular weight heparin (based on body weight), and antithrombin III, with or without the administration of selective cytokines inhibitors, is the most appropriate therapeutic approaches. Additionally, throughout the course of the disease, regardless of severity, the use of antioxidants must be included, such as acetylcysteine or carbocysteine which are readily available.

\section{Conclusion}

In conclusion, to facilitate administration of the most effective treatments, it is essential to correctly identify the stages of COVID-19 infection, and to select an appropriate and specific therapeutic protocol based on the most available data. As outlined in other disease models with similar immunopathology including ovarian cancer, severe COVID-19 therapies must target inflammation, oxidative stress, coagulation disorders, and nutritional status to improve patient outcomes. Recently, we have highlighted the fundamental need to modulate inflammation and related disorders to improve the outcomes of immunotherapies in patients with advanced cancer [162]. Hence, the potential role of checkpoint inhibitors, such as the programmed death (PD)-1 ligand, which its inhibition restores the function of exhausted lymphocytes, are being examined in these patients which could provide additional therapeutic perspectives [163]. 


\section{Abbreviations}

SARS-CoV-2: Severe acute respiratory syndrome coronavirus 2; COVID19: Corona Virus Disease 2019;" ARDS: Acute respiratory distress syndrome CRP: C-reactive protein; NLR: Neutrophil/lymphocyte ratio; IL: Interleukin; TNF: Tumor necrosis factor; ROS: Reactive oxygen species; IFNs: Interferons; ACE2: Angiotensin-converting enzyme 2; HIF: Hypoxia-inducible factor; STAT3: Signal transducer and activator of transcription 3; PI3K: Phosphatidylinositol-3-kinase; AKT: Protein kinase B; mTOR: Mammalian target of rapamycin; JAK: Janus kinase; SH2: Src Homology 2; TCR: T-cell receptor; NLRP3: Nucleotide-binding domain, leucine-rich-containing family, pyrin domain-containing-3; NF-kB: Nuclear factor kappa-light-chain-enhancer of activated B cells; mAb: Monoclonal antibody; AP: Adaptor protein; COX2: Cyclooxigenase-2; PD: Programmed death

\section{Acknowledgments}

Work supported by Associazione Sarda per la Ricerca in Ginecologia Oncologica. The authors thank Alison Schrooer for her assistance in preparing the figures. The authors thank Martina Mura for her technical and administrative assistance. The authors would thank Dr Paolo Cannas, General Manager of the "Azienda di Rilievo Nazionale ad Alta Specializzazione G Brotzu", for the encouragement in the development of this field of research during the pandemic period.

\section{Authors' contributions}

AM, SO and CM contributed to study design, data analysis, literature review, manuscript draft and final editing. The authors read and approved the final manuscript.

\section{Funding}

NA.

\section{Ethics approval and consent to participate}

NA.

\section{Consent for publication}

NA.

\section{Competing interests}

The authors have no competing interest to declare.

\section{Author details}

'Department of Gynecologic Oncology, Businco Hospital, "Azienda di Rilievo Nazionale ad Alta Specializzazione G. Brotzu", Via Jenner, 09100 Cagliari, Italy. ${ }^{2}$ Hematology and Transplant Center, Businco Hospital, "Azienda di Rilievo Nazionale ad Alta Specializzazione G. Brotzu", Cagliari, Italy. ${ }^{3}$ Department of Medical Sciences and Public Health, University of Cagliari, Cagliari, Italy.

Received: 11 November 2020 Accepted: 22 January 2021 Published online: 08 February 2021

\section{References}

1. Coronavirus disease (COVID-19) Weekly Epidemiological Update and Weekly Operational Update. November 6, 2020. https://www.who.int/emergencies/ diseases/novel-coronavirus-2019/situation-reports. (Accessed 6 Nov 2020).

2. Livingston E, Bucher K. Coronavirus disease 2019 (COVID-19) in Italy. JAMA. 2020;323:1335

3. Wu JT, Leung K, Bushman M, Kishore N, Niehus R, de Salazar PM, Cowling BJ, Lipsitch M, Leung GM. Estimating clinical severity of COVID-19 from the transmission dynamics in Wuhan, China. Nat Med. 2020;26:506-10.

4. Richardson S, Hirsch JS, Narasimhan M, Crawford JM, McGinn T, Davidson $\mathrm{KW}$, et al. Presenting characteristics, comorbidities, and outcomes among 5700 patients hospitalized with COVID-19 in the New York City area. JAMA. 2020:323:2052-9.

5. Huang C, Wang Y, Li X, Ren L, Zhao J, Hu Y, et al. Clinical features of patients infected with 2019 novel coronavirus in Wuhan, China. Lancet. 2020;395:497-506

6. Cordon-Cardo C, Pujadas E, Wajnberg A, Sebra R, Patel G, Firpo-Betancourt A, et al. COVID-19: staging of a new disease. Cancer Cell. 2020;38:594-7.

7. Wu C, Chen X, Cai Y, Xia J, Zhou X, Xu S, et al. Risk Factors Associated With Acute Respiratory Distress Syndrome and Death in Patients With
Coronavirus Disease 2019 Pneumonia in Wuhan, China. JAMA Intern Med 2020:e200994. https://doi.org/10.1001/jamainternmed.2020.0994.

8. Han H, Yang L, Liu R, Liu F, Wu KL, Li J, et al. Prominent changes in blood coagulation of patients with SARS-CoV-2 infection. Clin Chem Lab Med. 2020;58:1116-20.

9. Zhou F, Yu T, Du R, Fan G, Liu Y, Liu Z, et al. Clinical course and risk factors for mortality of adult inpatients with COVID-19 in Wuhan, China: a retrospective cohort study. Lancet. 2020;395:1054-62.

10. Qin C, Zhou L, Hu Z, Zhang S, Yang S, Tao Y, et al. Dysregulation of immune response in patients with COVID-19 in Wuhan, China. Clin Infect Dis. 2020;71:762-8.

11. Castro VM, McCoy TH, Perlis RH. Laboratory findings associated with severe illness and mortality among hospitalized individuals with coronavirus disease 2019 in eastern Massachusetts. JAMA Netw Open. 2020;3:e2023934.

12. Dolan RD, McSorley ST, Horgan PG, Laird B, McMillan DC. The role of the systemic inflammatory response in predicting outcomes in patients with advanced inoperable cancer: systematic review and meta-analysis. Crit Rev Oncol Hematol. 2017;116:134-46.

13. Mei Z, Shi L, Wang B, Yang J, Xiao Z, Du P, Wang Q, Yang W. Prognostic role of pretreatment blood neutrophil-to-lymphocyte ratio in advanced cancer survivors: a systematic review and meta-analysis of 66 cohort studies. Cancer Treat Rev. 2017;58:1-13.

14. Nie D, Gong H, Mao X, Li Z. Systemic immune-inflammation index predicts prognosis in patients with epithelial ovarian cancer: a retrospective study. Gynecol Oncol. 2019;152:259-64.

15. Yin $X, W u L$, Yang $H$, Yang $H$. Prognostic significance of neutrophillymphocyte ratio (NLR) in patients with ovarian cancer: a systematic review and meta-analysis. Medicine (Baltimore). 2019;98(45):e17475.

16. Huang QT, Zhou L, Zeng WJ, Ma QQ, Wang W, Zhong M, Yu YH. Prognostic significance of neutrophil-to-lymphocyte ratio in ovarian Cancer: a systematic review and meta-analysis of observational studies. Cell Physiol Biochem. 2017:41(6):2411-8.

17. Henriksen JR, Nederby L, Donskov F, Waldstrøm M, Adimi P, Jakobsen A, Steffensen KD. Prognostic significance of baseline T cells, B cells and neutrophil-lymphocyte ratio (NLR) in recurrent ovarian cancer treated with chemotherapy. J Ovarian Res. 2020;13(1):59.

18. Tang N, Li D, Wang X, Sun Z. Abnormal coagulation parameters are associated with poor prognosis in patients with novel coronavirus pneumonia. J Thromb Haemost. 2020;18:844-7.

19. Lagunas-Rangel FA. Neutrophil-to-lymphocyte ratio and lymphocyte-to-Creactive protein ratio in patients with severe coronavirus disease 2019 (COVID-19): a meta-analysis. J Med Virol. 2020. https://doi.org/10.1002/jmv. 25819.

20. Liu Y, Du X, Chen J, Jin Y, Peng L, Wang HHX, et al. Neutrophil-tolymphocyte ratio as an independent risk factor for mortality in hospitalized patients with COVID-19. J Inf Secur. 2020;81:e6-e12.

21. Liu J, Liu Y, Xiang P, Pu L, Xiong H, Li C, et al. Neutrophil-to-lymphocyte ratio predicts critical illness patients with 2019 coronavirus disease in the early stage. J Transl Med. 2020;18:206.

22. Metha P, McAuley DF, Brown M, Sanchez E, Tattersall RS, Manson JJ. COVID19: consider cytokine storm syndromes and immunodepression. Lancet. 2020;395:1033-4.

23. Terpos E, Ntanasis-Stathopoulos I, Elalamy I, Kastritis E, Sergentanis TN, Politou M, et al. Hematological findings and complications of COVID-19. Am J Hematol. 2020;95:834-47.

24. Macciò A, Lai P, Santona MC, Pagliara L, Melis GB, Mantovani G. High serum levels of soluble $\mathrm{IL}-2$ receptor, cytokines, and $\mathrm{C}$ reactive protein correlate with impairment of $\mathrm{T}$ cell response in patients with advanced epithelial ovarian cancer. Gynecol Oncol. 1998;69:248-52.

25. Macciò A, Madeddu C. The role of interleukin- 6 in the evolution of ovarian cancer: clinical and prognostic implications--a review. J Mol Med (Berl). 2013:91:1355-68.

26. Macciò A, Madeddu C. Inflammation and ovarian cancer. Cytokine. 2012;58: 133-47.

27. Macciò A, Madeddu C, Massa D, Astara G, Farci D, Melis GB, et al. Interleukin-6 and leptin as markers of energy metabolic changes in advanced ovarian cancer patients. J Cell Mol Med. 2009;13(9B):3951-9.

28. Macciò A, Madeddu C, Massa D, Mudu MC, Lusso MR, Gramignano G, et al. Hemoglobin levels correlate with interleukin-6 levels in patients with advanced untreated epithelial ovarian cancer: role of inflammation in cancer-related anemia. Blood. 2005;106:362-7. 
29. Macciò A, Madeddu C, Gramignano G, Mulas C, Floris C, Sanna E, et al. A randomized phase III clinical trial of a combined treatment for cachexia in patients with gynecological cancers: evaluating the impact on metabolic and inflammatory profiles and quality of life. Gynecol Oncol. 2012;124:417-25.

30. Macciò A, Madeddu C, Gramignano G, Mulas C, Tanca L, Cherchi MC, et al. The role of inflammation, iron, and nutritional status in cancer-related anemia: results of a large, prospective, observational study. Haematologica. 2015;100:124-32.

31. Taneri PE, Gómez-Ochoa SA, Llanaj E, Raguindin PF, Rojas LZ, Roa-Díaz ZM, et al. Anemia and iron metabolism in COVID-19: a systematic review and meta-analysis. Eur J Epidemiol. 2020;35:763-73.

32. Stone RL, Nick AM, McNeish IA, Balkwill F, Han HD, Bottsford-Miller J, et al. Paraneoplastic thrombocytosis in ovarian cancer. New Engl J Med. 2012;366: 610-8.

33. Gastl G, Plante M, Finstad CL, Wong GY, Federici MG, Bander NH, Rubin SC. High IL-6 levels in ascitic fluid correlate with reactive thrombocytosis in patients with epithelial ovarian cancer. Br J Haematol. 1993;83(3):433-41.

34. Reitter EM, Ay C, Kaider A, Pirker R, Zielinski C, Zlabinger G, Pabinger I. Interleukin levels and their potential association with venous thromboembolism and survival in cancer patients. Clin Exp Immunol. 2014; 177(1):253-60

35. Hisada Y, Mack N. Cancer-associated pathways and biomarkers of venous thrombosis. Blood. 2017;130(13):1499-506.

36. Medzhitov R, Schneider DS, Soares MP. Disease tolerance as a defense strategy. Science. 2012;335:936-41.

37. Turnquist C, Ryan BM, Horikawa I, Harris BT, Harris CC. Cytokine storms in Cancer and COVID-19. Cancer Cell. 2020;38(5):598-601.

38. Ayres JS. The biology of physiological health. Cell. 2020;181:250-69.

39. Ayres JS, Schneider DS. Two ways to survive an infection: what resistance and tolerance can teach us about treatments for infectious diseases. Nat Rev Immunol. 2008;8:889-95.

40. Rouse BT, Sehrawat S. Immunity and immunopathology to viruses: what decides the outcome? Nat Rev Immunol. 2010;10:514-26.

41. Tal MC, Sasai M, Lee HK, Yordy B, Shadel GS, Iwasaki A. Absence of autophagy results in reactive oxygen species-dependent amplification of RLR signaling. Proc Natl Acad Sci U S A. 2009;106:2770-5.

42. Incalza MA, D'Oria R, Natalicchio A, Perrini S, Laviola L, Giorgino F. Oxidative stress and reactive oxygen species in endothelial dysfunction associated with cardiovascular and metabolic diseases. Vasc Pharmacol. 2018;100:1-19.

43. Lillicrap D. Disseminated intravascular coagulation in patients with 2019nCoV pneumonia. J Thromb Haemost. 2020;18:786-7.

44. Guidotti LG, Rochford R, Chung J, Shapiro M, Purcell R, Chisari FV. Viral clearance without destruction of infected cells during acute HBV infection. Science. 1999;284:825-9.

45. Rehermann B. Hepatitis $C$ virus versus innate and adaptive immune responses: a tale of coevolution and coexistence. J Clin Invest. 2009;119: 1745-54.

46. Prompetchara E, Ketloy C, Palaga T. Immune responses in COVID-19 and potential vaccines: lessons learned from SARS and MERS epidemic. Asian Pac J Allergy Immunol. 2020;38:1-9.

47. Zhu N, Zhang D, Wang W, Li X, Yang B, Song J, et al. A novel coronavirus from patients with pneumonia in China, 2019. N Engl J Med. 2020;382:727-33.

48. Chu H, Chan JF, Wang Y, Yuen TT, Chai $Y$, Hou Y, et al. Comparative replication and immune activation profiles of SARS-CoV-2 and SARS-CoV in human lungs: an ex vivo study with implications for the pathogenesis of COVID-19. Clin Infect Dis. 2020;71:1400-9.

49. Perlman S, Dandekar AA. Immunopathogenesis of coronavirus infections: implications for SARS. Nat Rev Immunol. 2005;5:917-27.

50. Allard B, Panariti A, Martin JG. Alveolar macrophages in the resolution of inflammation, tissue repair, and tolerance to infection. Front Immunol. 2018; 9:1777.

51. Mantovani A, Allavena P, Sica A, Balkwill F. Cancer-related inflammation. Nature. 2008:454:436-44.

52. Larionova I, Tuguzbaeva G, Ponomaryova A, Stakheyeva M, Cherdyntseva N, Pavlov V, Choinzonov E, Kzhyshkowska J. Tumor-associated macrophages in human breast, colorectal, lung, ovarian and prostate cancers. Front Oncol. 2020;10:566511.

53. Gong $Y$, Yang J, Wang $Y$, Xue L, Wang J. Metabolic factors contribute to Tcell inhibition in the ovarian cancer ascites. Int J Cancer. 2020;147:1768-77.
54. Giuntoli RL 2nd, Webb TJ, Zoso A, Rogers O, Diaz-Montes TP, Bristow RE, Oelke M. Ovarian cancer-associated ascites demonstrates altered immune environment: implications for antitumor immunity. Anticancer Res. 2009;29: 2875-84.

55. Warburg O, Gawehn K, Geissler AW. Stoffwechsel der weissen Blutzellen [Metabolism of leukocytes]. Z Naturforsch B. 1958;13B(8):515-6.

56. Peri G, Polentarutti N, Sessa C, Mangioni C, Mantovani A. Tumoricidal activity of macrophages isolated from human ascitic and solid ovarian carcinomas: augmentation by interferon, lymphokines and endotoxin. Int J Cancer. 1981;28(2):143-52.

57. Mantovani A, Polentarutti N, Peri G, Shavit ZB, Vecchi A, Bolis G, Mangioni C Cytotoxicity on tumor cells of peripheral blood monocytes and tumorassociated macrophages in patients with ascites ovarian tumors. J Natl Cancer Inst. 1980;64(6):1307-15

58. Sheid B, Boyce J. Inhibition of lymphocyte mitogenesis by factor(s) released from macrophages isolated from ascitic fluid of advanced ovarian cancer patients. Cancer Immunol Immunother. 1984;17(3):190-4.

59. Robinson-Smith TM, Isaacsohn I, Mercer CA, Zhou M, Van Rooijen N, Husseinzadeh N, McFarland-Mancini MM, Drew AF. Macrophages mediate inflammation-enhanced metastasis of ovarian tumors in mice. Cancer Res. 2007:67(12):5708-16.

60. Hagemann T, Wilson J, Kulbe H, Li NF, Leinster DA, Charles K, Klemm F, Pukrop T, Binder C, Balkwill FR. Macrophages induce invasiveness of epithelial cancer cells via NF-kappa B and JNK. J Immunol. 2005;175(2): 1197-205.

61. Hagemann T, Wilson J, Burke F, Kulbe H, Li NF, Plüddemann A, Charles K, Gordon S, Balkwill FR. Ovarian cancer cells polarize macrophages toward a tumor-associated phenotype. J Immunol. 2006;176(8):5023-32.

62. Yuan X, Zhang J, Li D, Mao Y, Mo F, Du W, Ma X. Prognostic significance of tumor-associated macrophages in ovarian cancer: a meta-analysis. Gynecol Oncol. 2017;147(1):181-7

63. Madeddu C, Gramignano G, Kotsonis P, Coghe F, Atzeni V, Scartozzi M, Macciò A. Microenvironmental M1 tumor-associated macrophage polarization influences cancer-related anemia in advanced ovarian cancer: key role of interleukin-6. Haematologica. 2018;103:e388-91.

64. Macciò A, Gramignano G, Cherchi MC, Tanca L, Melis L, Madeddu C. Role of M1-polarized tumor-associated macrophages in the prognosis of advanced ovarian cancer patients. Sci Rep. 2020;10:6096.

65. Thorsson V, Gibbs DL, Brown SD, Wolf D, Bortone DS, Ou Yang TH, et al. The Immune Landscape of Cancer. Immunity. 2018;48(4):812-830.e14.

66. Channappanavar R, Perlman S. Pathogenic human coronavirus infections: causes and consequences of cytokine storm and immunopathology. Semin Immunopathol. 2017:39:529-39.

67. Kindler E, Thiel V, Weber F. Interaction of SARS and MERS coronaviruses with the antiviral interferon response. Adv Virus Res. 2016;96:219-43.

68. Wong LY, Lui PY, Jin DY. A molecular arms race between host innate antiviral response and emerging human coronaviruses. Virol Sin. 2016; 31:12-23.

69. Shokri S, Mahmoudvand S, Taherkhani R, Farshadpour F. Modulation of the immune response by Middle East respiratory syndrome coronavirus. J Cell Physiol. 2019;234:2143-51.

70. Piccolo V, Curina A, Genua M, Ghisletti S, Simonatto M, Sabò A, et al. Opposing macrophage polarization programs show extensive epigenomic and transcriptional crosstalk. Nat Immunol. 2017;18:530-40.

71. Macciò A, Madeddu C. Blocking inflammation to improve immunotherapy of advanced cancer. Immunology. 2020;159:357-64.

72. Yigit R, Massuger LF, Figdor CG, Torensma R. Ovarian cancer creates a suppressive microenvironment to escape immune elimination. Gynecol Oncol. 2010;117(2):366-72.

73. Martins R, Carlos AR, Braza F, Thompson JA, Bastos-Amador P, Ramos S, et al. Disease tolerance as an inherent component of immunity. Annu Rev Immunol. 2019:37:405-37.

74. Wang A, Huen SC, Luan HH, Yu S, Zhang C, Gallezot JD, et al. Opposing effects of fasting metabolism on tissue tolerance in bacterial and viral inflammation. Cell. 2016;166:1512-25.

75. Madeddu C, Mantovani G, Gramignano G, Macciò A. Advances in pharmacologic strategies for cancer cachexia. Expert Opin Pharmacother. 2015:16:2163-77.

76. Madeddu C, Mantovani G, Gramignano G, Astara G, Macciò A. Muscle wasting as main evidence of energy impairment in cancer cachexia: future therapeutic approaches. Future Oncol. 2015;11:2697-710. 
77. Macciò A, Madeddu C, Mantovani G. Current pharmacotherapy options for cancer anorexia and cachexia. Expert Opin Pharmacother. 2012;13:2453-72.

78. Mantovani G, Macciò A, Massa E, Madeddu C. Managing cancer-related anorexia/cachexia. Drugs. 2001;61:499-514.

79. Talks KL, Turley H, Gatter KC, Maxwell PH, Pugh CW, Ratcliffe PJ, Harris AL. The expression and distribution of the hypoxia-inducible factors HIF-1alpha and HIF-2alpha in normal human tissues, cancers, and tumor-associated macrophages. Am J Pathol. 2000;157(2):411-21.

80. Paolini L, Adam C, Beauvillain C, Preisser L, Blanchard S, Pignon P, et al. Lactic acidosis together with GM-CSF and M-CSF induces human macrophages toward an inflammatory Protumor phenotype. Cancer Immunol Res. 2020;8(3):383-95.

81. Duechler M, Peczek L, Szubert M, Suzin J. Influence of hypoxia inducible factors on the immune microenvironment in ovarian cancer. Anticancer Res. 2014;34(6):2811-9.

82. Corcoran SE, O'Neill LAJ. HIF1a and metabolic reprogramming in inflammation. J Clin Invest. 2016;26:3699-707.

83. Murray PJ, Allen JE, Biswas SK, Fisher EA, Gilroy DW, Goerdt S, et al. Macrophage activation and polarization: nomenclature and experimental guidelines. Immunity. 2014;1:14-20.

84. Italiani $\mathrm{P}$, Boraschi D. From monocytes to M1/M2 macrophages: Phenotypical vs. Functional Differentiation. Front Immunol. 2014;5:514.

85. Buck MD, Sowell RT, Kaech SM, Pearce EL. Metabolic instruction of immunity. Cell. 2017;169:570-86.

86. Xu S, Yu C, Ma X, Li Y, Shen Y, Chen Y, Huang S, Zhang T, Deng W, Wang Y. IL-6 promotes nuclear translocation of HIF-1a to aggravate chemoresistance of ovarian cancer cells.Eur J Pharmacol. 2021;894:173817.

87. Siu MKY, Jiang YX, Wang JJ, Leung THY, Han CY, Tsang BK, Cheung ANY, Ngan HYS, Chan KKL. Hexokinase 2 regulates ovarian Cancer cell migration, invasion and Stemness via FAK/ERK1/2/MMP9/NANOG/SOX9 signaling cascades. Cancers (Basel). 2019;11(6):813.

88. Watson JM, Sensintaffar JL, Berek JS, Martínez-Maza O. Constitutive production of interleukin 6 by ovarian cancer cell lines and by primary ovarian tumor cultures. Cancer Res. 1990;50(21):6959-65.

89. Lo CW, Chen MW, Hsiao M, Wang S, Chen CA, Hsiao SM, et al. IL-6 transsignaling in formation and progression of malignant ascites in ovarian cancer. Cancer Res. 2011;71:424-34.

90. Rabinovich A, Medina L, Piura B, Segal S, Huleihel M. Regulation of ovarian carcinoma SKOV-3 cell proliferation and secretion of MMPs by autocrine IL6. Anticancer Res. 2007;27:267-72.

91. Berek JS, Chung C, Kaldi K, Watson JM, Knox RM, Martínez-Maza O. Serum interleukin-6 levels correlate with disease status in patients with epithelial ovarian cancer. Am J Obstet Gynecol. 1991;164(4):1038-42.

92. Lane D, Matte I, Rancourt C, Piché A. Prognostic significance of IL-6 and IL-8 ascites levels in ovarian cancer patients. BMC Cancer. 2011;11:210.

93. Coward J, Kulbe H, Chakravarty P, Leader D, Vassileva V, Leinster DA, et al. Interleukin-6 as a therapeutic target in human ovarian cancer. Clin Cancer Res. 2011;17:6083-96.

94. Jehn CF, Kühnhardt D, Bartholomae A, Pfeiffer S, Schmid P, Possinger K, et al. Association of IL-6, hypothalamus-pituitary-adrenal axis function, and depression in patients with cancer. Integr Cancer Ther. 2010;9:270-5.

95. Lamkin DM, Lutgendorf SK, Lubaroff D, Sood AK, Beltz TG, Johnson AK. Cancer induces inflammation and depressive-like behavior in the mouse: modulation by social housing. Brain Behav Immun. 2011;25(3):555-64.

96. Pyter LM, Pineros V, Galang JA, McClintock MK, Prendergast BJ. Peripheral tumors induce depressive-like behaviors and cytokine production and alter hypothalamic-pituitary-adrenal axis regulation. Proc Natl Acad Sci U S A. 2009;106(22):9069-74.

97. Lutgendorf SK, Weinrib AZ, Penedo F, Russell D, DeGeest K, Costanzo ES, Henderson PJ, Sephton SE, Rohleder N, Lucci JA 3rd, Cole S, Sood AK, Lubaroff DM. Interleukin-6, cortisol, and depressive symptoms in ovarian cancer patients. J Clin Oncol. 2008;26(29):4820-7.

98. Clevenger L, Schrepf A, Christensen D, DeGeest K, Bender D, Ahmed A, Goodheart MJ, Penedo F, Lubaroff DM, Sood AK, Lutgendorf SK. Sleep disturbance, cytokines, and fatigue in women with ovarian cancer. Brain Behav Immun. 2012;26(7):1037-44.

99. Schrepf A, Clevenger L, Christensen D, DeGeest K, Bender D, Ahmed A, et al. Cortisol and inflammatory processes in ovarian cancer patients following primary treatment: relationships with depression, fatigue, and disability. Brain Behav Immun. 2013:30(Suppl (0)):S126-34.
100. Toledo C, Andrade DC, Díaz HS, Inestrosa NC, Del Rio R. Neurocognitive disorders in heart failure: novel pathophysiological mechanisms underpinning memory loss and learning impairment. Mol Neurobiol. 2019; 56:8035-51.

101. Serrano F, Klann E. Reactive oxygen species and synaptic plasticity in the aging hippocampus. Ageing Res Rev. 2004;3:431-43.

102. Heinrich PC, Castell JV, Andus T. Interleukin- 6 and the acute phase response. Biochem J. 1990;265:621-36.

103. Erroi A, Sironi M, Chiaffarino F, Chen ZG, Mengozzi M, Mantovani A. IL-1 and IL-6 release by tumor-associated macrophages from human ovarian carcinoma. Int J Cancer. 1989:44(5):795-801.

104. Zhang Y, Wang X, Li X, Xi D, Mao R, Wu X, Cheng S, Sun X, Yi C, Ling Z, Ma L, Ning Q, Fang Y, Sun B, Wu D. Potential contribution of increased soluble IL-2R to lymphopenia in COVID-19 patients. Cell Mol Immunol. 2020;17(8): 878-80.

105. Tormo AJ, Letellier MC, Sharma M, Elson G, Crabé S, Gauchat JF. IL-6 activates STAT5 in T cells. Cytokine. 2012;60:575-82.

106. Blay JY, Negrier S, Philip T, Favrot M, Mercatello A. Pretreatment serum CRP and response to interleukin 2. Br J Cancer. 1994;69:200-1.

107. Vachino G, Gelfand JA, Atkins MB, Tamerius JD, Demchak P, Mier JW. Complement activation in cancer patients undergoing immunotherapy with interleukin-2 (IL-2): binding of complement and C-reactive protein by IL-2activated lymphocytes. Blood. 1991;78:2505-13.

108. Hamoudi WH, Baum LL. Anti-C-reactive protein inhibits the calcium-dependent stage of natural killer cell activation. J Immunol. 1991;146:2873-8.

109. White JP, Puppa MJ, Gao S, Sato S, Welle SL, Carson JA. Muscle mTORC1 suppression by IL-6 during cancer cachexia: a role for AMPK. Am J Physiol Endocrinol Metab. 2013;304:E1042-52

110. Diao B, Wang C, Tan Y, Chen X, Liu Y, Ning L, Chen L, Li M, Liu Y, Wang G, Yuan Z, Feng Z, Zhang Y, Wu Y, Chen Y. Reduction and functional exhaustion of T cells in patients with coronavirus disease 2019 (COVID-19). Front Immunol. 2020;11:827.

111. Muñoz-Cánoves P, Scheele C, Pedersen BK, Serrano AL. Interleukin-6 myokine signaling in skeletal muscle: a double-edged sword? FEBS J. 2013; 280:4131-48.

112. Pin F, Barreto $R$, Kitase $Y$, Mitra $S$, Erne CE, Novinger LJ, Zimmers TA, Couch ME, Bonewald LF, Bonetto A. Growth of ovarian cancer xenografts causes loss of muscle and bone mass: a new model for the study of cancer cachexia. J Cachexia Sarcopenia Muscle. 2018;9(4):685-700.

113. Anker MS, Landmesser U, von Haehling S, Butler J, Coats AJS, Anker SD. Weight loss, malnutrition, and cachexia in COVID-19: facts and numbers. J Cachexia Sarcopenia Muscle. 2020. https://doi.org/10.1002/jcsm.12674.

114. Radigan KA, Nicholson TT, Welch LC, Chi M, Amarelle L, Angulo M, et al. Influenza a virus infection induces muscle wasting via IL-6 regulation of the E3 ubiquitin ligase Atrogin-1. J Immunol. 2019;202:484-93.

115. Zhai S, Hu L, Zhong L, Guo Y, Dong L, Jia R, Wang Z. Respiratory syncytial virus aggravates renal injury through cytokines and direct renal injury. Front Cell Infect Microbiol. 2016;6:112.

116. Mantovani G, Macciò A, Madeddu C, Mura L, Gramignano G, Lusso MR, et al. Quantitative evaluation of oxidative stress, chronic inflammatory indices and leptin in cancer patients: correlation with stage and performance status. Int J Cancer. 2002;98:84-91.

117. Mantovani G, Macciò A, Madeddu C, Mura L, Massa E, Gramignano G, et al. Reactive oxygen species, antioxidant mechanisms and serum cytokine levels in cancer patients: impact of an antioxidant treatment. J Cell Mol Med. 2002;6:570-82.

118. Lötscher J, Balmer ML. Sensing between reactions - how the metabolic microenvironment shapes immunity. Clin Exp Immunol. 2019;197:161-9.

119. Song M, Sandoval TA, Chae CS, et al. IRE1alpha- XBP1 controls T cell function in ovarian cancer by regulating mitochondrial activity. Nature. 2018:562:423-8.

120. Mantovani G, Macciò A, Melis G, Mura L, Massa E, Mudu MC. Restoration of functional defects in peripheral blood mononuclear cells isolated from cancer patients by thiol antioxidants alpha-lipoic acid and $\mathrm{N}$-acetyl cysteine. Int J Cancer. 2000;86:842-7.

121. Mantovani G, Macciò A, Madeddu C, Mura L, Gramignano G, Lusso MR, et al. Antioxidant agents are effective in inducing lymphocyte progression through cell cycle in advanced cancer patients: assessment of the most important laboratory indexes of cachexia and oxidative stress. J Mol Med (Berl). 2003:81:664-73. 
122. Mantovani G, Macciò A, Madeddu C, Mura L, Gramignano G, Lusso MR, et al. The impact of different antioxidant agents alone or in combination on reactive oxygen species, antioxidant enzymes and cytokines in a series of advanced cancer patients at different sites: correlation with disease progression. Free Radic Res. 2003;37:213-23.

123. Mantovani G, Macciò A, Madeddu C, Gramignano G, Lusso MR, Serpe R, et al. A phase II study with antioxidants, both in the diet and supplemented, pharmaconutritional support, progestagen, and anticyclooxygenase-2 showing efficacy and safety in patients with cancerrelated anorexia/cachexia and oxidative stress. Cancer Epidemiol Biomark Prev. 2006;15:1030-4.

124. Macciò A, Gramignano G, Madeddu C. A multitargeted treatment approach for Anemia and Cachexia in metastatic castration-resistant prostate Cancer. J Pain Symptom Manag. 2015;50:e1-4.

125. Macciò A, Madeddu C, Panzone F, Mantovani G. Carbocysteine: clinical experience and new perspectives in the treatment of chronic inflammatory diseases. Expert Opin Pharmacother. 2009;10:693-703.

126. Gross O, Thomas CJ, Guarda G, Tschopp J. The inflammasome: an integrated view. Immunol Rev. 2011;243:136-51.

127. Franceschi C, Bonafe M, Valensin S, Olivieri F, De Luca M, Ottaviani E, De Benedictis $\mathrm{G}$. Inflammaging. An evolutionary perspective on immunosenescence. Ann N Y Acad Sci. 2000;908:244-54.

128. Ershler WB, Keller ET. Age-associated increased interleukin-6 gene expression, late-life diseases, and frailty. Annu Rev Med. 2000;51:245-70.

129. Ferrucci L, Semba RD, Guralnik JM, Ershler WB, Bandinelli S, Patel KV, et al. Proinflammatory state, hepcidin, and anemia in older persons. Blood. 2010; 115:3810-6.

130. Luborsky J, Barua A, Edassery S, Bahr JM, Edassery SL. Inflammasome expression is higher in ovarian tumors than in normal ovary. PLoS One. 2020;15(1):e0227081.

131. Bauckman K, Haller E, Taran N, Rockfield S, Ruiz-Rivera A, Nanjundan M. Iron alters cell survival in a mitochondria-dependent pathway in ovarian cancer cells. Biochem J. 2015;466(2):401-13.

132. Bauckman KA, Haller E, Flores I, Nanjundan M. Iron modulates cell survival in a Ras- and MAPK-dependent manner in ovarian cells. Cell Death Dis. 2013; 4(4):e592.

133. Shi Y, He R, Yang Y, He Y, Zhan L, Wei B. Potential relationship between Sirt3 and autophagy in ovarian cancer. Oncol Lett. 2020;20(5):162.

134. Droge W, Schipper HM. Oxidative stress and aberrant signaling in aging and cognitive decline. Aging Cell. 2007:6:361-70.

135. Macciò A, MAdeddu C. Management of Anemia of inflammation in the elderly. Anemia. 2012;2012:563251.

136. Morgan MJ, Liu ZG. Crosstalk of reactive oxygen species and NF-KB signaling. Cell Res. 2011;21:103-15.

137. Ye SM, Johnson RW. Regulation of interleukin- 6 gene expression in brain of aged mice by nuclear factor B. J Neuroimmunol. 2001;117:87-96.

138. Boe DM, Boule LA, Kovacs EJ. Innate immune responses in the ageing lung. Clin Exp Immunol. 2017;187:16-25.

139. Madeddu C, Gramignano G, Tanca L, Cherchi MC, Floris CA, MAcciò A. A combined treatment approach for cachexia and cancer-related anemia in advanced cancer patients: A randomized placebo-controlled trial. J Clin Oncol. 2014;31(suppl):189.

140. Macciò A, Madeddu C, Gramignano G, Mulas C, Sanna E, Mantovani G. Efficacy and safety of oral lactoferrin supplementation in combination with rHuEPO-beta for the treatment of anemia in advanced cancer patients undergoing chemotherapy: open-label, randomized controlled study. Oncologist. 2010;15:894-902.

141. Ledford $\mathrm{H}$. Coronavirus breakthrough: dexamethasone is first drug shown to save lives. Nature. 2020;582(7813):469.

142. RECOVERY Collaborative Group, Horby P, Lim WS, Emberson JR, Mafham M, Bell JL, Linsell L, et al. Dexamethasone in hospitalized patients with COVID19 - preliminary report. N Engl J Med. 2020 Jul 17:NEJMoa2021436. https:// doi.org/10.1056/NEJMoa2021436. Epub ahead of print.

143. WHO Rapid Evidence Appraisal for COVID-19 Therapies (REACT) Working Group, Sterne JAC, Murthy S, Diaz JV, Slutsky AS, Villar J, Angus DC, et al. Association Between Administration of Systemic Corticosteroids and Mortality Among Critically III Patients With COVID-19: A Meta-analysis. JAMA 2020;324:1330-41.

144. Hermine O, Mariette X, Tharaux P, Resche-Rigon M, Porcher R, Ravaud P. Effect of Tocilizumab vs Usual Care in Adults Hospitalized With COVID-19 and Moderate or Severe Pneumonia: A Randomized Clinical
Trial. JAMA Intern Med. 2020:e206820. https://doi.org/10.1001/ jamainternmed.2020.6820.

145. Salvarani C, Dolci G, Massari M, Merlo DF, Cavuto S, Savoldi L, et al. Effect of tocilizumab vs standard of care on clinical worsening in patients hospitalized with COVID-19 pneumonia: a randomized clinical trial. JAMA Intern Med. 2020:e206615. https://doi.org/10.1001/jamainternmed.2020.6615.

146. Gupta S, Wang W, Hayek SS, Chan L, Mathews KS, Melamed ML, et al. Association between early treatment with tocilizumab and mortality among critically ill patients with COVID-19. JAMA Intern Med. 2020:e206252. https:// doi.org/10.1001/jamainternmed.2020.6252.

147. Salama C, Han J, Yau L, Reiss WG, Kramer B, Neidhart JD, et al. Tocilizumab in patients hospitalized with Covid-19 pneumonia. N Engl J Med. 2020. https://doi.org/10.1056/NEJMoa2030340.

148. Parr JB. Time to reassess Tocilizumab's role in COVID-19 pneumonia. JAMA Intern Med. 2020. https://doi.org/10.1001/jamainternmed.2020.6557.

149. Crisafulli S, Isgrò V, La Corte L, Atzeni F, Trifirò G. Potential role of antiinterleukin (IL)-6 drugs in the treatment of COVID-19: rationale, clinical evidence and risks. BioDrugs. 2020;34(4):415-22.

150. La Rosée F, Bremer HC, Gehrke I, Kehr A, Hochhaus A, Birndt S, Fellhauer M, Henkes M, Kumle B, Russo SG, La Rosée P. The Janus kinase 1/2 inhibitor ruxolitinib in COVID-19 with severe systemic hyperinflammation. Leukemia. 2020;34(7):1805-15.

151. Liu STH, Lin HM, Baine I, Wajnberg A, Gumprecht JP, Rahman F, et al. Convalescent plasma treatment of severe COVID-19: a propensity scorematched control study. Nat Med. 2020;26(11):1708-13.

152. Tuccori M, Ferraro S, Convertino I, Cappello E, Valdiserra G, Blandizzi C, Maggi F, Focosi D. Anti-SARS-CoV-2 neutralizing monoclonal antibodies: clinical pipeline. MAbs. 2020;12(1):1854149.

153. Kupferschmidt K, Cohen J. Race to find COVID-19 treatments accelerates. Science. 2020;367:1412-3.

154. Beigel JH, Tomashek KM, Dodd LE, Mehta AK, Zingman BS, Kalil AC, et al. Remdesivir for the treatment of Covid-19 - preliminary report. N Engl J Med. 2020:383:1813-26.

155. Kalil AC, Patterson TF, Mehta AK, Tomashek KM, Wolfe CR, Ghazaryan V, et al. Baricitinib plus Remdesivir for hospitalized adults with Covid-19. N Engl J Med. 2020. https://doi.org/10.1056/NEJMoa2031994.

156. Polack FP, Thomas SJ, Kitchin N, et al. Safety and efficacy of the BNT162b2 Covid-19 vaccine. N Engl J Med. https://doi.org/10.1056/NEJMoa2034577.

157. Mahase E. Covid-19: Moderna vaccine is nearly $95 \%$ effective, trial involving high risk and elderly people shows. BMJ. 2020;371:m4471. https://doi.org/10. 1136/bmi.m4471.

158. Voysey M, Clemens SAC, Madhi SA, et al. Safety and efficacy of the ChAdOx1 nCoV-19 vaccine (AZD1222) against SARS-CoV-2: an interim analysis of four randomised controlled trials in Brazil, South Africa, and the UK. Lancet. 2020. https://doi.org/10.1016/S0140-6736(20)32661-1.

159. Baghaki S, Yalcin CE, Baghaki HS, Aydin SY, Daghan B, Yavuz E. COX2 inhibition in the treatment of COVID-19: review of literature to propose repositioning of celecoxib for randomized controlled studies. Int J Infect Dis. 2020;101:29-32.

160. https://www.recoverytrial.net/files/recovery-protocol-v12-1-2020-12-16.pdf; Accessed on 30 Dec 2020

161. FitzGerald GA. Misguided drug advice for COVID-19. Science. 2020;367:1434

162. Macciò A, Madeddu C. Future prospects for PD-1 targeting, macrophage infiltration, and IDO pathway activation in patients with sarcomas. JAMA Oncol. 2018:4:1134.

163. Di Cosimo S, Malfettone A, Pérez-García JM, Llombart-Cussac A, Miceli R, Curigliano G, Cortés J. Immune checkpoint inhibitors: a physiology-driven approach to the treatment of coronavirus disease 2019. Eur J Cancer. 2020; 135:62-5.

\section{Publisher's Note}

Springer Nature remains neutral with regard to jurisdictional claims in published maps and institutional affiliations. 